WellBeing International

WBI Studies Repository

$1-2014$

\title{
Acoustic Divergence in the Rut Vocalizations of Persian and European Fallow Deer
}

\author{
J. B. Stachowicz \\ University of Zürich \\ E. Vannoni \\ University of Zürich \\ B. J. Pitcher \\ Queen Mary University of London \\ Elodie F. Briefer \\ Queen Mary University of London \\ E. Geffen \\ Tel Aviv University
}

See next page for additional authors

Follow this and additional works at: https://www.wellbeingintlstudiesrepository.org/acwp_vsm

Part of the Animal Structures Commons, Animal Studies Commons, and the Other Animal Sciences Commons

\section{Recommended Citation}

Stachowicz, J. B., Vannoni, E., Pitcher, B. J., Briefer, E. F., Geffen, E., \& McElligott, A. G. (2014). Acoustic divergence in the rut vocalizations of Persian and European fallow deer. Journal of Zoology, 292(1), 1-9.

This material is brought to you for free and open access by WellBeing International. It has been accepted for inclusion by an authorized administrator of the WBI Studies Repository. For more information, please contact wbisr-info@wellbeingintl.org.

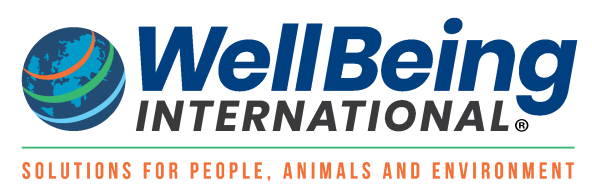




\section{Authors}

J. B. Stachowicz, E. Vannoni, B. J. Pitcher, Elodie F. Briefer, E. Geffen, and A. G. McElligott 


\title{
Acoustic Divergence in the Rut Vocalizations of Persian and European Fallow Deer
}

\author{
J.B. Stachowicz ${ }^{1}$, E. Vannoni ${ }^{1}$, B.J. Pitcher ${ }^{2}$, E.F. Briefer ${ }^{2,4}$, E. Geffen ${ }^{3}$, and A. G. McElligott ${ }^{2}$ \\ ${ }^{1}$ University of Zürich \\ ${ }^{2}$ Queen Mary University of London \\ ${ }^{3}$ Tel Aviv University \\ ${ }^{4}$ ETH Zürich
}

\section{$\underline{\text { KEYWORDS }}$}

Dama dama, Dama mesopotamica, fundamental frequency, formant frequency, phylogeny, sexual selection, source-filter theory, vocal communication

\section{$\underline{\text { ABSTRACT }}$}

We conducted a study of the male rut vocalizations (groans) of two closely related species, Persian and European fallow deer. Persian fallow deer are endangered, restricted to Iran and Israel, and their rut vocalizations have never been studied. By contrast, European fallow deer are one of the most common deer species in the world, and have been the subject of numerous detailed studies. Persian bucks are approximately 16\% larger than European bucks, and this can have important implications for vocalizations. Persian bucks were recorded in Israel, and European bucks were recorded in the UK and Ireland. We measured temporal, fundamental frequency-related and formant-related parameters of groans and determined which acoustic parameters differed among species and populations. The comparisons revealed important structural similarities and differences, with the differences more strongly related to temporal than spectral vocal parameters. Persian buck groans were relatively long, pulsed calls of almost 1-s duration, with low fundamental frequencies, and relatively weak formant modulation. European buck groans were much shorter $(0.38 \mathrm{~s})$, but with similarly low fundamental frequencies and clearer formant modulation. We found some minor differences in the formant frequencies (F4 and F5) of calls of the two European fallow populations. Given the length of time since Persian and European fallow deer diverged, and that both their mitochondrial and nuclear genomes are very different, it is notable that the structure of their groans is still so similar. Our findings suggest that the factors influencing the evolution of these vocalizations (e.g. sensory system characteristics, environment and mate choice) have probably been similar for both species.

\section{Introduction}

Vocal communication is used to regulate social interactions, including those linked to sexual selection (Andersson, 1994). The sexually selected calls of males function in attracting mates and repelling 
competitors (Reby \& McComb, 2003a; Briefer, Vannoni \& McElligott, 2010; Koren \& Geffen, 2011). The source-filter theory of call production has become the standard approach for examining the acoustic parameters of mammal vocalizations. It is advantageous because it links an animal's morphology and physiology, to its vocal parameters (Taylor \& Reby, 2010; Briefer \& McElligott, 2011).

Call structure in mammals results from a two-stage source-filter process linked to the larynx and vocal tract (Taylor \& Reby, 2010). The air expelled from the lungs causes vibrations of the vocal folds in the larynx, and generates the glottal wave ('source'). The rate of these vibrations determines the fundamental frequency (F0, Taylor \& Reby, 2010). The sound then passes through the supralaryngeal vocal tract and nasal cavities and gets filtered. This filtering determines the vocal tract resonances or formant frequencies (Taylor \& Reby, 2010; Briefer \& McElligott, 2011). The sound that finally emanates from an animal results from this source-filter process. Body size is also linked to lung capacity, which is an important determinant of call duration (Fitch, 2006). Using the source-filter approach when examining the calls of a species that has not been previously studied, allows direct and detailed comparisons with more well-known ones (Cap et al., 2008; Kidjo et al., 2008; Frey \& Riede, 2013).

The fallow deer genus Dama diverged from the Cervinae, and later split into two species during the Pliocene epoch; between 4.13 and 2.85 MYA (Persian fallow deer Dama mesopotamica and European fallow deer Dama dama; Gilbert, Ropiquet \& Hassanin, 2006; Hassanin et al., 2012). Until recently, questions remained about whether the two types were distinct enough to be considered species or subspecies (Fernández-García, 2012). However, we now know that they are sufficiently divergent to be considered true species (Hassanin et al., 2012). Both originate from West Eurasia (Persian fallow deer, e.g. Iran, Israel and Turkey, Saltz et al., 2011; European fallow deer, Turkey and possibly Greece, Masseti, Pecchioli \& Vernesi, 2008). Persian fallow deer are extinct in most of their former range. Small populations exist in Iran (remnant) and Israel (reintroduced), but the species remains classified as endangered (Saltz et al., 2011; Fernández-García, 2012; IUCN, 2012). By contrast, European fallow deer are probably the most widespread deer species in the world, as a result of introductions (Chapman \& Chapman, 1997). However, only small numbers remain of its original, most genetically diverse source populations in Turkey and Greece (Masseti et al., 2008). Both species are size dimorphic, have polygynous mating systems, and the males ('bucks') only vocalize ('groan') during the breeding season (Chapman \& Chapman, 1997; Thirgood, Langbein \& Putman, 1999).

In the northern hemisphere, European fallow bucks start to vocalize at the end of September and continue until early November. They can reach calling rates of over 3000 groans per hour (McElligott \& Hayden, 1999). Groaning is used to attract females, as well as to deter competing males (McElligott, O'Neill \& Hayden, 1999; Reby \& McComb, 2003b; Vannoni \& McElligott, 2008; Charlton \& Reby, 2011). During groaning, bucks retract their larynges and thereby extend their vocal tracts (McElligott, Birrer \& Vannoni, 2006). This results in lower formant frequencies, which has been linked to selection for acoustic size exaggeration (Fitch \& Reby, 2001; McElligott et al., 2006). Vocal communication (and other breeding behaviours) of Persian fallow deer have not been studied previously. However, it is known that matings take place approximately two months earlier in Persian fallow deer (Iran and Israel) than in European fallow deer in the UK and Ireland; during the second half of August compared with the latter half of October, respectively (Chapman \& Chapman, 1997).

Persian and European fallow deer are morphologically similar and capable of producing fertile hybrid offspring (Asher et al., 1996). One of the main differences is in body size, with Persian fallow considered larger (Chapman \& Chapman, 1997). Typically for ungulates, the length of a segment of one hind leg is used as an indicator of overall body size (McElligott et al., 2001). The average size of this hind leg measurement is approximately $37 \mathrm{~cm}$ for Persian fallow bucks (A.G. McElligott, unpubl. data) and $32 \mathrm{~cm}$ for European bucks (Vannoni \& McElligott, 2008); thereby suggesting that Persian bucks are 
approximately $16 \%$ larger than European bucks. The other most noticeable difference is that Persian bucks have smaller antlers, with almost no 'palms' compared with European bucks (Chapman \& Chapman, 1997; Ciuti \& Apollonio, 2011).

Species with large geographic distributions can develop variation in their vocalizations and/or sexually selected traits (Attard et al., 2010). These are usually caused by a combination of genetic, behavioural and/or ecological differences (Janik \& Slater, 1997; Slabbekoorn \& Smith, 2002; Cap et al., 2008). However, to date, variation in the vocalizations of very widely distributed European fallow bucks has only been examined at the individual level (Reby et al., 1998; Vannoni \& McElligott, 2007), and the question as to whether geographic differences already exist in the calls of populations separated only for hundreds of years (Sykes, 2004), has not been investigated.

We investigated the sexually selected calls of both Persian and European fallow bucks. Persian fallow bucks were recorded in Israel, and European fallow buck recordings were taken in the UK and Ireland. There have been some concerns that the Persian fallow deer in Israel were hybrids of the two species. However, it is now known that the Persian fallow deer in Israel are not hybrids (Fernández-García, 2012). Our first aim was to provide a detailed study of Persian fallow buck calls. We then investigated the parameters that are potentially responsible for differences between the two deer species, and between two different European fallow populations (Reby \& McComb, 2003a; Vannoni \& McElligott, 2008). We predicted that differences between the two species would be greater than those within the two populations of European fallow deer. Our study has the potential to assist with understanding how the vocalizations of closely related species are influenced by sexual selection and other factors.

\section{Materials and methods}

\section{Study locations and species}

Persian fallow bucks were recorded during 2011 in captivity at Hai Bar Carmel Nature Reserve (HBCNR), Israel $\left(32^{\circ} 45^{\prime} \mathrm{N}, 35^{\circ} 00^{\prime} \mathrm{E}\right)$. European fallow deer recordings were taken in Petworth Park, UK (283 ha, $50^{\circ} 59^{\prime} \mathrm{N}, 0^{\circ} 36^{\prime} \mathrm{W}$ ) during 2011, and Phoenix Park, Ireland (707 ha, 53 $21^{\prime} \mathrm{N}, 6^{\circ} 19^{\prime} \mathrm{W}$ ), during 2000, 2002, 2003 and 2004. Weather conditions during data collection in Israel (August) and the two sites in the UK and Ireland (October) differed greatly. The mean monthly daytime temperature maximum for the Israeli site was $30^{\circ} \mathrm{C}$, whereas for the UK and Ireland, it was 16 and $13^{\circ} \mathrm{C}$, respectively (Israel, http://www.ims.gov.il/; UK, http://www.metoffice.gov.uk/; Ireland, http://www.met.ie/).

Persian fallow deer numbered 106 individuals (55 males, 51 females). They were in three adjacent enclosures (two mixed-sex and one male-only, 2-3 ha each) containing groups of various sizes. A single mating was observed on August 14, 2011. The population size of European fallow deer in Petworth Park was approximately 700 (B.J. Pitcher, unpubl. data), and the Phoenix Park population ranged from 600 to 700 (Vannoni, Torriani \& McElligott, 2005). All males (HBCNR = 6, Petworth Park = 6, Phoenix Park = 13) were known or estimated to be older than 4 years and individually identifiable (McElligott et al., 1999).

\section{Sound recording}

Recordings were carried out between dawn and dusk at distances of 20-100 m. Vocalizations were recorded using a Sennheiser MKH70 microphone, connected either to a Marantz recorder (PMD661) or a Sony DAT recorder (DATTCD D100). Persian bucks were recorded from all three enclosures between August 14 and 31, 2011. Because the Persian bucks showed no loss of body condition (J. Stachowicz, pers. obs.), it was unlikely that they experienced fatigue (Vannoni \& McElligott, 2009). Therefore we included groans from the whole period in the analyses. European fallow buck groans were recorded 
between October 4 and 19; thus minimizing the possibility that the call parameters were affected by fatigue (McElligott et al., 2003; Vannoni \& McElligott, 2009).

\section{Acoustic analysis}

Recordings were transferred to a computer (sampling rate: $44.1 \mathrm{kHz}$, amplitude resolution: 16 bit) and saved in WAV format. Then, the narrowband spectrogram (window length: $0.04 \mathrm{~s}$, number of time steps: 1000 , number of frequency steps: 250 , Gaussian window shape, dynamic range: $45 \mathrm{~dB}$ ) of each groan was created using PRAAT (Boersma \& Weenink, 2011). Groans with high levels of background noise were discarded.

We analysed 128 groans recorded from 6 Persian bucks, 52 groans from 6 European bucks (Petworth Park), and 137 groans from 13 European bucks (Phoenix Park). The mean number of analysed groans per individual was $12.68 \pm 1.45$. To minimize pseudoreplication, most groans were extracted from different calling bouts (Reby, Cargnelutti \& Hewison, 1999). For a small number of males, this was not possible because of low numbers of recordings; $12 / 128$ (9.38\%) of Persian buck groans and 4/52 (7.69\%) of European buck groans from Petworth Park were selected from the same bout. These were not consecutive and were separated by at least five other groans. We used multiple groans from single bouts for two Phoenix Park bucks, but only $12.41 \%$ of Phoenix Park groans were consecutive. Because we examined species-level differences and not individuality, any pseudoreplication effects should be minimal.

Source-, filter- and temporal-related parameters were extracted and measured using PRAAT (Boersma \& Weenink, 2011). Groan duration, the number of pulses, and the interpulse intervals were measured directly on the waveform for each groan (Fig. 1). The inverse of the inter-pulse intervals provides the fundamental frequency (F0). FOmin and FOmax were obtained directly using this approach; Fomean was calculated from the other F0 values.

We estimated the minimum frequencies of the first six formants (F1-F6) using Linear Predictive Coding analysis (LPC) [Sound: To Formant (burg) command] in PRAAT. For a more accurate measurement of all six formants, we conducted several detailed LPC analyses for each groan (Briefer et al., 2010). Formant values were plotted against time and frequency, and compared with the narrow band spectrogram of each groan in order to check if PRAAT accurately tracked the formants. We then calculated the minimum frequencies of the first six formants (F1-F6 $\mathrm{min}$ ) by averaging their frequency values over the middle or last part of the call, when they had reached a minimum value (Reby \& McComb, 2003a; McElligott et al., 2006). Finally, the formant frequency spacing (formant dispersion, Df) and the corresponding vocal tract length (VTL) were estimated according to Reby \& McComb (2003b).

\section{Statistical analysis}

We first investigated which acoustic parameters differed between the species and populations using linear mixed effects models with maximum likelihood (Crawley, 2007). Each comparison (species and population) was analysed in separate models and $P$-values were used to evaluate significance. Individuals were fitted as random factors to control for repeated sampling. We carried out further $2 \times 2$ comparisons between European fallow deer populations using Bonferroni-Holm correction to avoid potential type I errors (Rice, 1989).

We conducted a nested permuted discriminant function analysis (pDFA) to verify if groans could be correctly classified to groups (species, population) by controlling for recordings from multiple individuals (Mundry \& Sommer, 2007). Before conducting the pDFA, we performed a principal component analysis (PCA) to eliminate redundancy among the parameters (12 in total) because of high intercorrelation (Jolliffe, 2005). PCs with eigenvalues greater than 1 (Kaiser's criterion) were then used as variables in the 
pDFA. It was not possible to measure all acoustic parameters in each call and therefore, missing values were replaced by the average of each variable for a given individual for the PCA and pDFA (15.28\% data replaced). In order to prevent this procedure from overly affecting the results, we reduced the number of calls for the PCA and pDFA, by mainly keeping calls in which all parameters could be measured (species: $N=229$; populations: $N=173$ ). Normal distributions of the data were determined by visually inspecting Q-Q plots and scatterplots of the residuals of the dependent variables. Some variables were then logtransformed to reach normal distributions (see Table 2). All statistical tests were carried out using $R$ version 2.14.0 (R Development Core Team, 2012). All tests were two-tailed, except the pDFA, which was one-tailed (because of the predicted direction of results; Mundry \& Sommer, 2007), and significance levels were set at 0.05 .

Figure 1. Waveform of a Persian fallow deer groan. The total duration of the groan (duration), the first and last pulse (P1 and P20) as well as the inter-pulse interval are indicated.

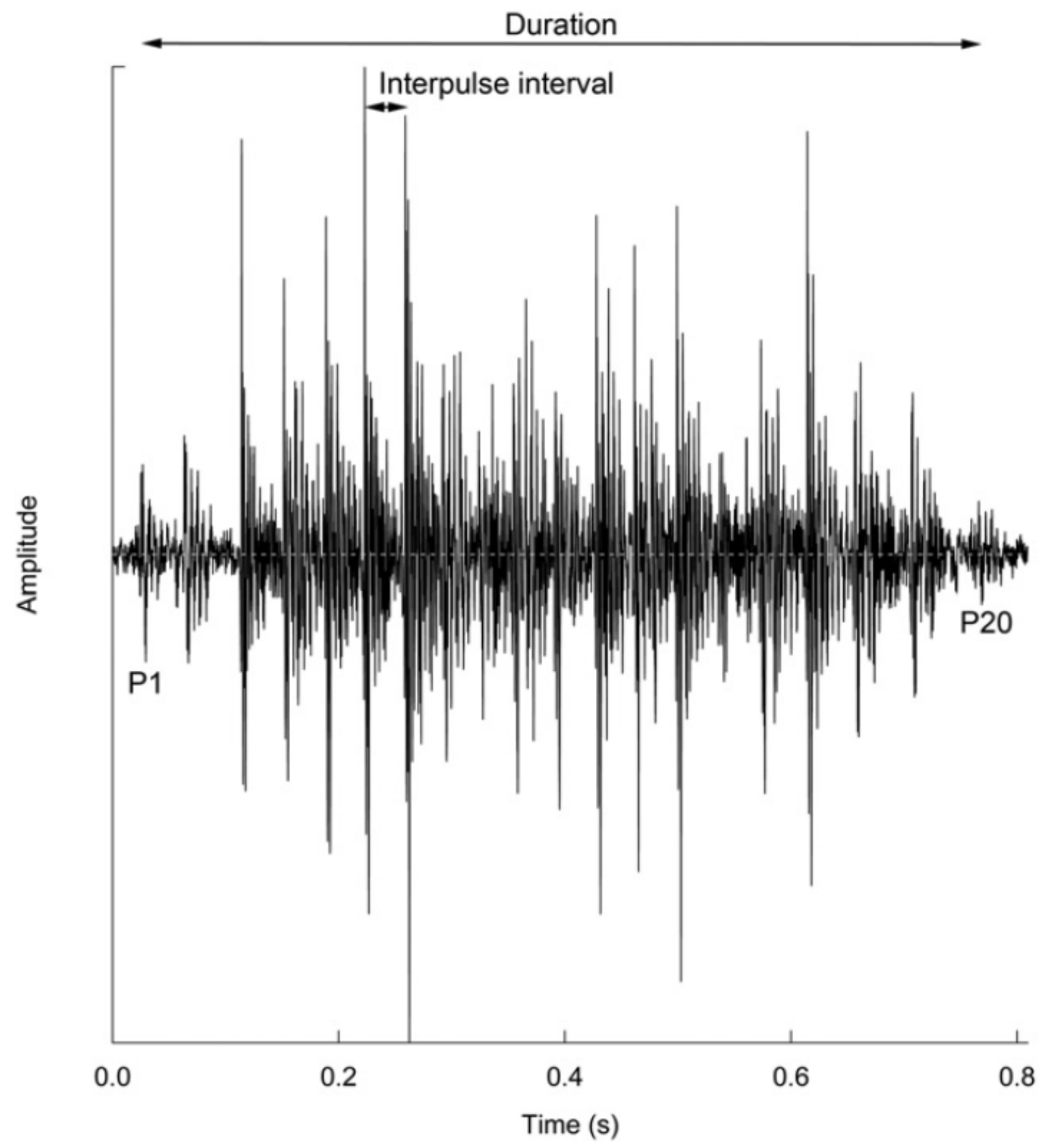


Figure 2. Spectrograms and waveforms of a common groan from a Persian fallow buck and a European fallow buck (Petworth Park). The first six formants (F1-F6) and examples of pulses are indicated by arrows.
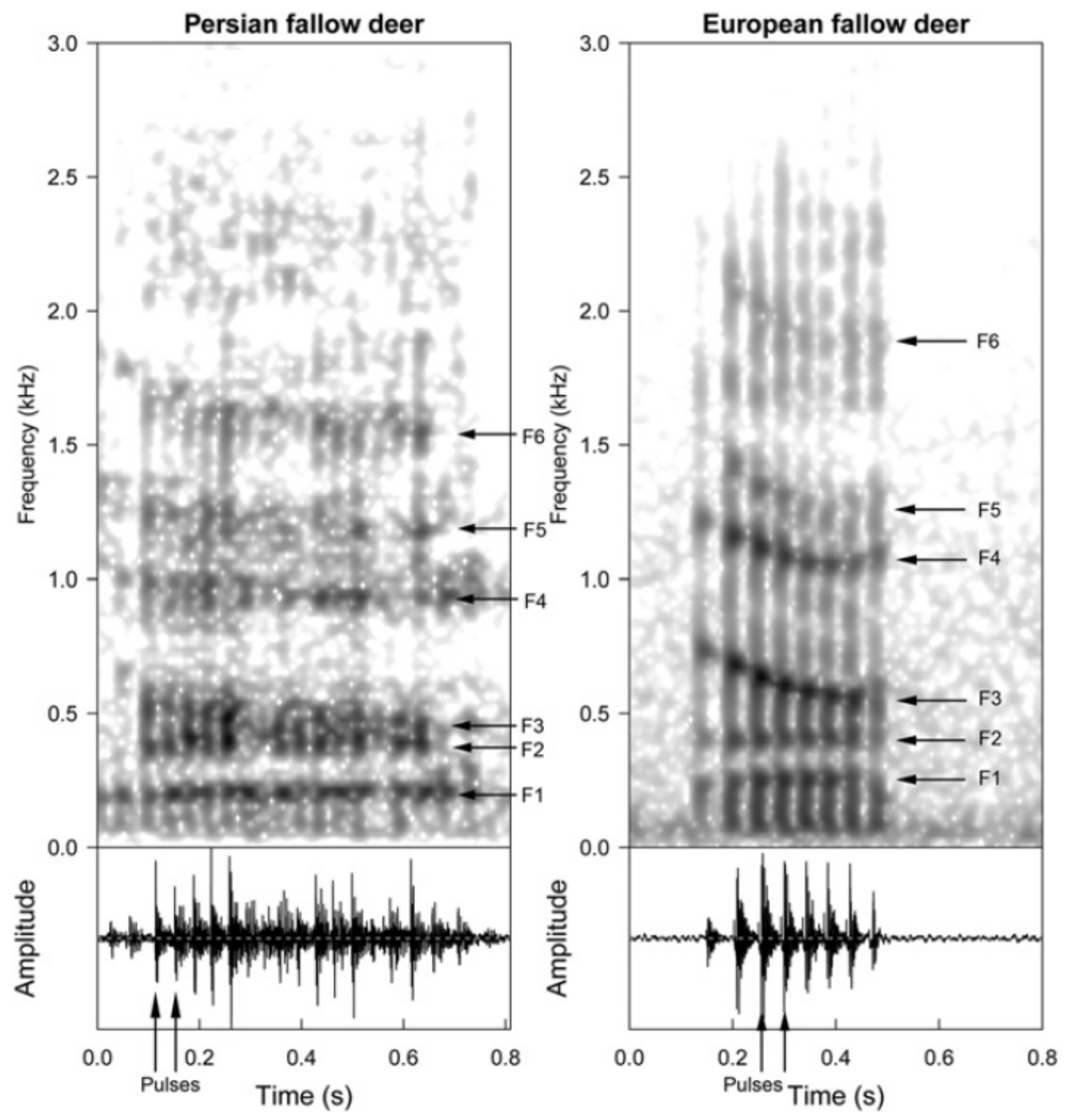

\section{Results}

Acoustic structure of Persian buck groans

Persian fallow buck common groans are relatively noisy calls, slightly less than 1-s long, with visible pulses and low F0. Six formants were present below $2600 \mathrm{~Hz}$ (Fig. 2, Table 1, Supporting Information S1). The first two formants remained flat across the groan whereas the upper formants (3-6) decreased after the start (Fig. 2). In a small proportion of cases (11\%, 14/128), formant frequencies increased towards the end of the call. On rare occasions $(n=13)$, bucks $(4 / 6)$ produced harsh groans. Harsh groans were noisier, and the pulses, formants and the formant decrease were less defined (Fig. 3). They were not used for detailed analyses because of their rarity. The highest call rate achieved by a Persian buck was 34 per minute (mean $=8.80 \pm 0.88, N=75$ groaning rates, $N=6$ males). 
Table 1. Acoustic parameters of Persian and European fallow deer groans: F0, F1-F6, Df, estVTLmax, call duration and number of pulses.

\begin{tabular}{|c|c|c|c|c|c|c|c|c|c|c|c|c|}
\hline \multirow[b]{3}{*}{ Variables } & & & & & \multicolumn{8}{|c|}{ European fallow } \\
\hline & \multicolumn{4}{|c|}{ Persian fallow } & \multicolumn{4}{|c|}{ Petworth Park } & \multicolumn{4}{|c|}{ Phoenix Park } \\
\hline & $\begin{array}{l}\text { Number } \\
\text { of calls }\end{array}$ & Range & Mean & SE & $\begin{array}{l}\text { Number } \\
\text { of calls }\end{array}$ & Range & Mean & SE & $\begin{array}{l}\text { Number } \\
\text { of calls }\end{array}$ & Range & Mean & SE \\
\hline $\mathrm{FO}_{\min }(\mathrm{Hz})$ & 128 & $\begin{array}{l}13.51- \\
27.52\end{array}$ & 19.97 & 0.29 & 52 & $\begin{array}{l}14.60- \\
34.93\end{array}$ & 22.1 & 0.59 & 137 & $\begin{array}{l}16.29- \\
32.66\end{array}$ & 21.46 & 0.26 \\
\hline $\mathrm{FO}_{\text {mean }}(\mathrm{Hz})$ & 128 & $\begin{array}{l}19.88- \\
37.57\end{array}$ & 27.97 & 0.28 & 52 & $\begin{array}{l}21.67- \\
40.36\end{array}$ & 27.22 & 0.66 & 137 & $\begin{array}{l}8.93- \\
37.81\end{array}$ & 25.92 & 0.34 \\
\hline $\mathrm{FO}_{\max }(\mathrm{Hz})$ & 128 & $\begin{array}{l}24.22- \\
70.51\end{array}$ & 37.99 & 0.76 & 52 & $\begin{array}{l}23.94- \\
51.97\end{array}$ & 32.85 & 0.99 & 137 & $\begin{array}{l}20.70- \\
45.33\end{array}$ & 30.79 & 0.48 \\
\hline $\mathrm{F} 1_{\min }(\mathrm{Hz})$ & 117 & $\begin{array}{l}149.18- \\
401.27\end{array}$ & 240.91 & 6.62 & 52 & $\begin{array}{l}174.67- \\
271.71\end{array}$ & 234.75 & 2.57 & 125 & $\begin{array}{l}176.17- \\
286.96\end{array}$ & 219.59 & 1.75 \\
\hline $\mathrm{F} 2_{\min }(\mathrm{Hz})$ & 116 & $\begin{array}{l}244.24- \\
690.11\end{array}$ & 465.96 & 11.21 & 52 & $\begin{array}{l}394.21- \\
446.44\end{array}$ & 418.68 & 1.69 & 133 & $\begin{array}{l}329.00- \\
482.28\end{array}$ & 415.19 & 1.87 \\
\hline$F 3_{\min }(\mathrm{Hz})$ & 109 & $\begin{array}{l}446.19- \\
1086.37\end{array}$ & 771.19 & 22.87 & 52 & $\begin{array}{l}477.24- \\
682.93\end{array}$ & 566.51 & 6.49 & 126 & $\begin{array}{l}501.88- \\
659.14\end{array}$ & 579.5 & 3.11 \\
\hline $\mathrm{F} 4_{\min }(\mathrm{Hz})$ & 106 & $\begin{array}{l}864.31- \\
1476.35\end{array}$ & 1137.68 & 18.96 & 52 & $\begin{array}{l}1025.04- \\
1189.46\end{array}$ & 1080.05 & 4.63 & 137 & $\begin{array}{l}961.49- \\
1126.31\end{array}$ & 1048.87 & 2.9 \\
\hline $\mathrm{F} 5_{\min }(\mathrm{Hz})$ & 89 & $\begin{array}{l}1021.02- \\
2075.31\end{array}$ & 1497.69 & 38.6 & 52 & $\begin{array}{l}1227.08- \\
1401.58\end{array}$ & 1291.08 & 4.52 & 135 & $\begin{array}{l}1174.28- \\
1340.61\end{array}$ & 1256.06 & 2.79 \\
\hline $\mathrm{F} 6_{\min }(\mathrm{Hz})$ & 51 & $\begin{array}{l}1484.16- \\
2576.03\end{array}$ & 1878.17 & 56.22 & 49 & $\begin{array}{l}1656.10- \\
1946.36\end{array}$ & 1808.26 & 8.86 & 130 & $\begin{array}{l}1683.65- \\
1923.53\end{array}$ & 1795.61 & 4.34 \\
\hline $\mathrm{Df}_{\min }(\mathrm{Hz})$ & 38 & $\begin{array}{l}255.00- \\
448.26\end{array}$ & 330.75 & 12.46 & 49 & $\begin{array}{l}288.09- \\
323.33\end{array}$ & 304.04 & 0.92 & 127 & $\begin{array}{l}283.39- \\
317.30\end{array}$ & 299.58 & 0.64 \\
\hline $\begin{array}{l}\text { estVTL } L_{\max } \\
(\mathrm{cm})\end{array}$ & 38 & $\begin{array}{l}39.04- \\
68.63\end{array}$ & 55.49 & 1.86 & 49 & $\begin{array}{l}54.12- \\
60.74\end{array}$ & 57.57 & 0.17 & 127 & $\begin{array}{l}55.15- \\
61.75\end{array}$ & 58.45 & 0.13 \\
\hline Duration (s) & 126 & $0.45-1.87$ & 0.9 & 0.03 & 52 & $\begin{array}{l}0.20- \\
0.64\end{array}$ & 0.37 & 0.01 & 137 & $\begin{array}{l}0.22- \\
0.76\end{array}$ & 0.38 & 0.01 \\
\hline $\begin{array}{l}\text { Number of } \\
\text { pulses }\end{array}$ & 124 & $13-48$ & 24.75 & 0.86 & 52 & $6-20$ & 10.15 & 0.48 & 137 & $6-20$ & 10.17 & 0.22 \\
\hline
\end{tabular}

F0, fundamental frequency; F1-F6, frequencies of the first six formants; Df, formant dispersion; estVTLmax, estimated vocal tract length; SE, standard error.

\section{Variation in Persian and European buck groans}

Persian bucks produced longer calls, with more pulses and higher F0max than European bucks (Tables 1 and 2). FOmin and FOmean, Formants 1-6, Df and the estVTLmax did not differ (Table 2). The PCA generated three components (PC1-PC3) with eigenvalues greater than one (Table 3). These components accounted for $83 \%$ of variation in the original data. Filter-related parameters (F1-F6, Df) were highly correlated with PC1, and F0-parameters (F0min, F0mean, F0max) with PC2. Temporal parameters (number of pulses and duration) were grouped in PC3 (Table 3), F0min also correlated with PC3, and number of pulses with PC1. Groans were correctly classified to species (pDFA: number of correctly crossclassified elements $=125.18 / 129(97.04 \%), P<0.001)$. Therefore the groans of Persian and European fallow bucks could be clearly distinguished (Fig. 4). 


\section{Variation in groans of European fallow bucks}

The minimum frequencies of formants F1, F4 and F5 were higher in calls by Petworth bucks (Supporting Information S2) compared with Phoenix Park (Tables 1 and 2). We found no other differences.

Four components (PC1-PC4) that exceeded eigenvalues greater than one were generated (Table 3), accounting for $77 \%$ of variation in the original data. Formants F1-F3 were correlated with PC4, whereas the upper formants (F4-F6) were correlated with PC1. F5 and Df were also correlated with PC2. F0min, F0mean and F0max were correlated with PC1 and PC2. The number of pulses and duration were grouped in PC3 (Table 3). Groans were correctly classified to the appropriate populations (pDFA: number of correctly cross-classified elements $=52.99 / 75(70.65 \%), P=0.037)$. This shows that although the groans of bucks from the two populations were very similar, they could still be distinguished (Fig. 4).

Figure 3. Spectrograms and waveforms of a harsh groan from a Persian fallow buck and a European fallow buck (Petworth Park). The first six formants (F1-F6) and examples of pulses are indicated by arrows.
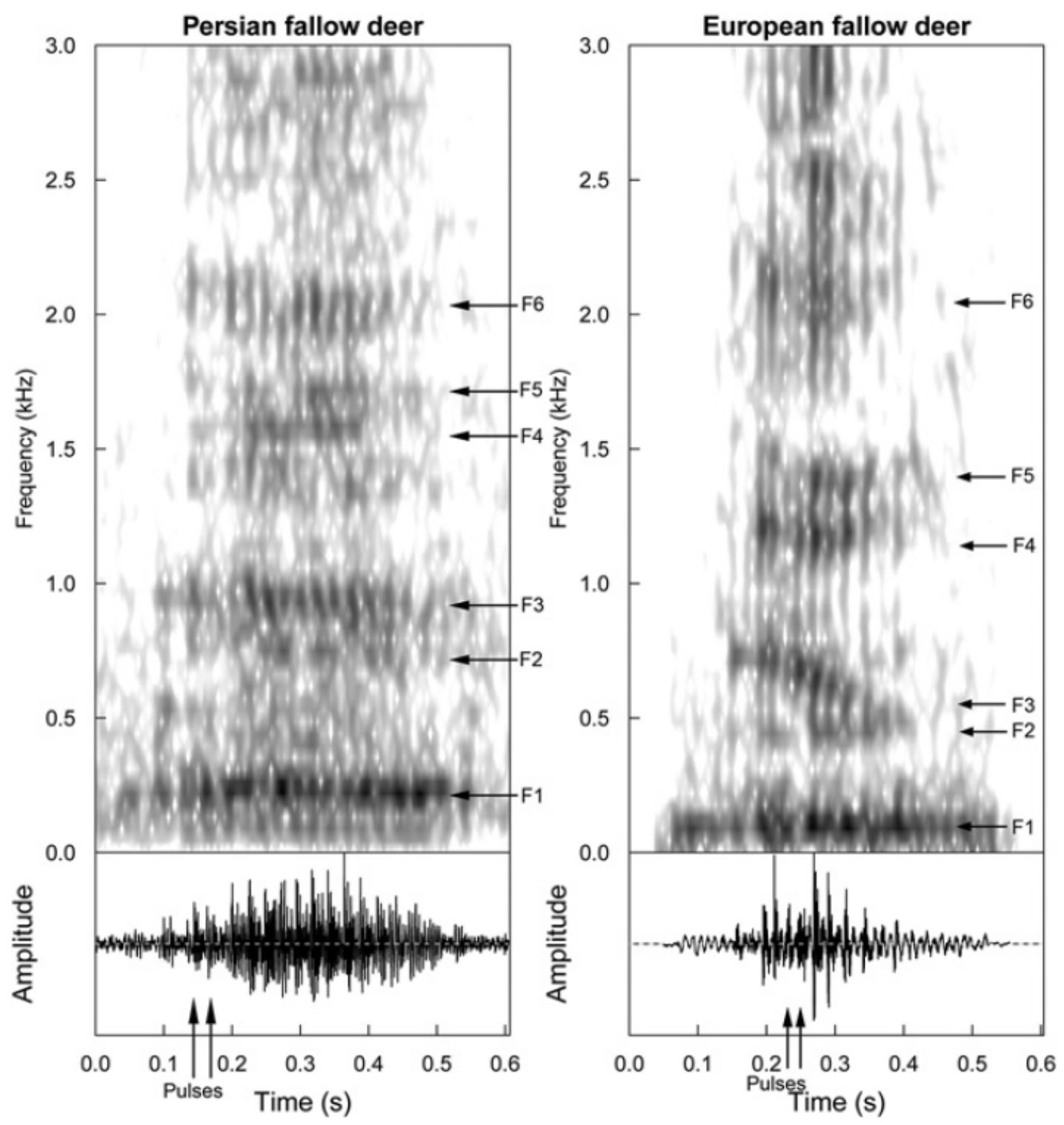
Table 2 Comparison of groan acoustic parameters between Persian and European fallow deer, and between two populations of European fallow deer (Petworth Park, UK and Phoenix Park, Ireland): F0, F1-F6, Df, estVTLmax, call duration and number of pulses

\begin{tabular}{|c|c|c|c|c|c|c|}
\hline \multirow[b]{3}{*}{ Acoustic variable } & \multirow{2}{*}{\multicolumn{3}{|c|}{ Persian vs. European fallow deer }} & \multicolumn{3}{|c|}{ European fallow deer } \\
\hline & & & & \multicolumn{3}{|c|}{ Petworth vs. Phoenix } \\
\hline & N calls & $F_{1,23}$ & $\boldsymbol{P}$ & $\mathbf{N}$ & $F_{1,17}$ & $\boldsymbol{P}$ \\
\hline $\mathrm{FO}_{\min }(\mathrm{Hz})$ & 125 & 1.88 & 0.18 & 189 & 0.58 & 0.46 \\
\hline $\mathrm{FO}_{\text {mean }}(\mathrm{Hz})$ & 125 & 1.21 & 0.28 & 189 & 1.21 & 0.29 \\
\hline $\mathrm{FO}_{\max }(\mathrm{Hz})$ & 125 & 7.91 & 0.01 & 189 & 1.23 & 0.28 \\
\hline $\mathrm{F} 1_{\min }(\mathrm{Hz})$ & 117 & 0.87 & 0.36 & 177 & 8.25 & 0.01 \\
\hline $\mathrm{F} 2 \mathrm{~min}_{\min }(\mathrm{Hz})$ & 116 & 0.4 & 0.54 & 185 & 0.23 & 0.64 \\
\hline $\mathrm{F} 3_{\min }(\mathrm{Hz})$ & 109 & 1.88 & 0.13 & 178 & 1.33 & 0.26 \\
\hline $\mathrm{F} 4_{\min }(\mathrm{Hz})$ & 106 & 0.04 & 0.84 & 189 & 7.47 & 0.01 \\
\hline $\mathrm{F} 5_{\min }(\mathrm{Hz})$ & 89 & 2.53 & 0.13 & 187 & 7.02 & 0.02 \\
\hline $\mathrm{F} 6_{\min }(\mathrm{Hz})$ & 51 & 0.06 & 0.81 & 179 & 0.21 & 0.65 \\
\hline $\mathrm{Df}_{\min }(\mathrm{Hz})$ & 38 & 2.14 & 0.16 & 176 & 1.86 & 0.19 \\
\hline estVTL $L_{\max }(\mathrm{cm})$ & 38 & 1.07 & 0.31 & 176 & 0.32 & 0.19 \\
\hline Duration (s) & 126 & 87.92 & $<0.001$ & 189 & 0.32 & 0.58 \\
\hline Number of pulses & 124 & 9.11 & $<0.001$ & 189 & 0.01 & 0.99 \\
\hline
\end{tabular}

F0, fundamental frequency; F1-F6, frequencies of the first six formants; Df, formant dispersion; estVTLmax, estimated vocal tract length.

Results from the linear mixed effects models with maximum likelihood.

Bold types indicate significant $P$-values. The following variables were log transformed when we compared Persian and European calls: F0mean, F0max, F1, F3, F4, F5, F6, Df, estVTLmax and duration. The following variables were log transformed when we compared the two populations of European fallow deer: F0min, F0mean, F0max, F2 and duration.

\section{Discussion}

We carried out a comparative study of the sexually selected calls of Persian and European fallow bucks. The interspecific and intraspecific comparisons revealed both important structural similarities and differences, but overall, the species and populations could be distinguished (Fig. 4). Persian buck groans were relatively long pulsed calls of almost 1-s duration, with low fundamental frequencies, and relatively weak formant modulation. European buck groans were much shorter (approximately $0.38 \mathrm{~s}$ ), but with similarly low fundamental frequencies and clearer formant modulation. There were also minor differences in the formants of the calls of the two European fallow populations. Given the time since Persian and European fallow deer diverged, and that their mitochondrial and nuclear genomes are very different (Gilbert et al., 2006; Hassanin et al., 2012), it is remarkable that the structure of their groans is still so similar. Because their geographical ranges have probably not overlapped (Masseti et al., 2008; Saltz et al., 2011), it may help explain why call structure linked to species recognition has not diverged more. The evolution of species-specific vocalizations is usually driven by factors such as the sensory system characteristics, environment and mate choice (Endler, 1992; Reby \& McComb, 2003b; Braune, Schmidt \& Zimmermann, 2008). Our findings suggest that these influences have probably been similar for both species.

We have provided the first study of the pulsed, relatively long common groans of Persian fallow bucks. It has been suggested that producing pulsed calls helps European fallow bucks produce high call rates (Vannoni \& McElligott, 2007). However, the mean call rate achieved by Persian bucks was nine groans 
per minute, which is far lower than the call rates of European bucks (often $>40$ per minute; McElligott \& Hayden, 1999). Therefore, as well as assisting with high call rates, the pulsed groans of Persian buck may also facilitate the production of longer calls. Compared with most other deer rut vocalizations $(<0.5 \mathrm{~s}$ duration; Cap et al., 2008), Persian buck groans are longer. They also have low fundamental frequencies that may aid the perception of formant frequencies (Kewley-Port et al., 1996). Persian bucks occasionally produced harsh groans, and these are likely to have an 'attention grabbing' function (Vannoni \& McElligott, 2007; Reby \& Charlton, 2012).

Table 3 Loadings of the groan acoustic parameters on the three and four principle components with eigenvalues $>1$, comparing Persian and European fallow buck groans

\begin{tabular}{|c|c|c|c|c|c|c|c|}
\hline \multirow[b]{4}{*}{ Acoustic variables } & & & & \multicolumn{4}{|c|}{ European fallow deer } \\
\hline & \multicolumn{3}{|c|}{ Persian vs. European fallow deer } & \multicolumn{4}{|c|}{ Petworth vs. Phoenix } \\
\hline & \multicolumn{3}{|c|}{ Components } & & & & \\
\hline & 1 & 2 & 3 & 1 & 2 & 3 & 4 \\
\hline $\mathrm{FO}_{\min }(\mathrm{Hz})$ & -0.16 & 0.72 & -0.52 & 0.63 & -0.52 & 0.31 & -0.04 \\
\hline $\mathrm{F} 0_{\text {mean }}(\mathrm{Hz})$ & 0.21 & -0.95 & 0.01 & -0.66 & 0.67 & -0.25 & 0.10 \\
\hline $\mathrm{FO}_{\max }(\mathrm{Hz})$ & 0.15 & -0.88 & -0.26 & -0.63 & 0.66 & -0.17 & 0.09 \\
\hline $\mathrm{F} 1_{\min }(\mathrm{Hz})$ & 0.71 & 0.19 & 0.26 & -0.03 & 0.18 & 0.03 & -0.76 \\
\hline $\mathrm{F} 2_{\min }(\mathrm{Hz})$ & -0.86 & -0.08 & -0.05 & 0.18 & -0.07 & -0.13 & -0.66 \\
\hline $\mathrm{F} 3_{\min }(\mathrm{Hz})$ & 0.85 & 0.21 & 0.11 & -0.18 & 0.43 & 0.15 & -0.48 \\
\hline $\mathrm{F} 4_{\text {min }}(\mathrm{Hz})$ & 0.82 & -0.002 & 0.36 & 0.75 & 0.44 & -0.009 & 0.16 \\
\hline $\mathrm{F} 5_{\min }(\mathrm{Hz})$ & 0.92 & 0.07 & 0.07 & -0.59 & -0.58 & -0.17 & 0.20 \\
\hline $\mathrm{F} 6_{\min }(\mathrm{Hz})$ & 0.91 & 0.04 & 0.17 & 0.65 & 0.46 & -0.15 & 0.27 \\
\hline$D f_{\min }(\mathrm{Hz})$ & -0.94 & -0.04 & 0.08 & 0.74 & 0.64 & -0.04 & 0.04 \\
\hline Duration & 0.41 & 0.04 & -0.87 & -0.07 & 0.06 & 0.97 & 0.06 \\
\hline Number of pulses & -0.60 & 0.14 & 0.76 & 0.41 & -0.36 & -0.78 & -0.10 \\
\hline Eigenvalues & 2.42 & 1.52 & 1.38 & 1.83 & 1.63 & 1.35 & 1.19 \\
\hline$\%$ Variance explained & 0.49 & 0.19 & 0.15 & 0.28 & 0.22 & 0.15 & 0.12 \\
\hline
\end{tabular}

F0, fundamental frequency; F1-F6, frequencies of the first six formants; Df, formant dispersion.

Bold types indicate the heaviest factor loadings, a cutoff point of $|r|=0.50$ was used to include a variable in a component. The eigenvalues of each component and their explained variance are given at the bottom of the table. Persian bucks $N=6,56$ groans; European bucks $N=19,173$ groans (Petworth bucks $N=6,51$ groans; Phoenix bucks $N=13,122$ groans).

Persian fallow bucks have a descended and mobile larynx, which they lower during common groans (Supporting Information S1). It is evident from the within-groan decreasing formant frequencies (particularly formants 4-6), as the length of the vocal tract increases during a groan (Fig. 2). Because Persian bucks are larger than European ones, with vocal tracts that are also longer, we expected Persian calls to have lower formant frequencies. However, finding similar formant frequencies in the two species suggests that Persian bucks do not lower their larynges to the maximum extent as European bucks during groaning. Lowering of the larynx results in decreased formant frequencies and has been hypothesized to exaggerate body size perception (Fitch \& Reby, 2001; McElligott et al., 2006).

The most striking differences between Persian and European fallow groans were in the temporal parameters; Persian groans were much longer, with lower numbers of pulses. The larger body size and therefore lung volume of Persian bucks might enable them to produce longer calls (Fitch, 2006). The lower groan rates (average, 9 per minute) of Persian fallow bucks compared with the groaning rates of 
European fallow bucks, probably partially result from the individual groans of Persian bucks being more than double the duration of European ones. European bucks are capable of maintaining calling rates greater than 40 per minute and more for extended periods (McElligott \& Hayden, 1999). The differences in call duration, call rates and numbers of pulses of Persian compared with European bucks could be attributed to naturally occurring differences between these species. Nevertheless, the captive breeding centre where we recorded Persian bucks may also have been a factor. Call rates of European bucks are at their highest when mature bucks are interacting with oestrous females and other mature calling males are nearby. This is an indicator of threat and motivation levels (McElligott \& Hayden, 1999; Charlton \& Reby, 2011). However, because the deer population at HBCNR was relatively small, with fewer oestrous females, the level of threat from intrasexual competition was lower. Nevertheless, it is unlikely that this difference accounted for all of the parameter differences that we detected. Observing and recording Persian bucks with larger social groups should help resolve this question.

Figure 4. Differences between groans of Persian and European fallow bucks, and between European fallow bucks from Petworth and Phoenix Park. Principle Components generated from the principal component analysis are plotted against each other. The areas represent calculated centroids of all acoustic parameters and the shading indicates different groups. Persian fallow buck groans are represented on the right side of the figure, and European fallow buck groans on the left (light shading, Petworth Park; dark shading, Phoenix Park).

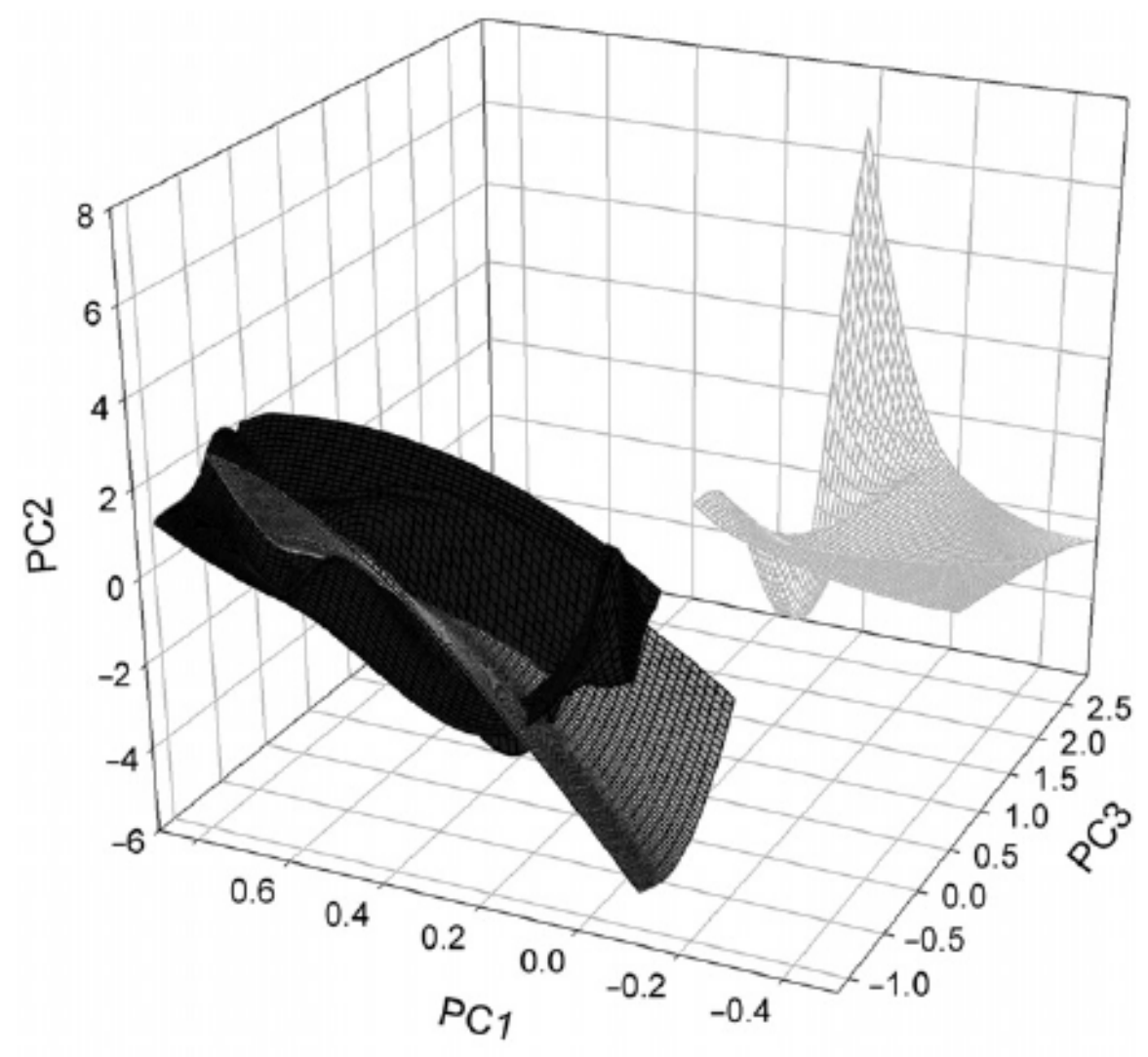

Dama mesopotamica

Dama dama - Petworth Park

Dama dama - Phoenix Park 
The average temperature during the rut for Persian bucks were approximately double that for European bucks ( 30 vs. 16 and $13^{\circ} \mathrm{C}$, for HBCNR, Petworth and Phoenix Park, respectively). It is therefore possible that the low groan rates of Persian bucks were partially caused by very warm local temperatures, and the potential for activity to cause overheating (Frey et al., 2012).

Fundamental and formant frequency parameters were similar in the two species, even though they were still useful for distinguishing them (Tables 2 and 3). These similarities, despite an approximate divergence time of over three million years (Hassanin et al., 2012), suggest the existence of similar factors driving the evolution of vocalizations in the two species (Reby \& McComb, 2003b).

We found that although the groans of the two European fallow populations were very similar they could still be distinguished. There were minor differences in some formants (Table 2; Fig. 4); higher in Petworth (Supporting Information S2) compared with Phoenix Park bucks. This could result from two main proximate factors, linked to body size or retraction of the larynx. Higher formants may indicate that Petworth Park males are marginally smaller than Phoenix Park males (Vannoni \& McElligott, 2008), despite no differences in the estimated VTLs (Table 2). Higher formants in Petworth groans may also indicate that these males did not retract their larynges to as great an extent as Phoenix Park bucks. All Petworth recordings were taken from lekking males (B.J. Pitcher, unpubl. data; Supporting Information S2) and the differences may represent a trade-off between the need to maintain high vocalization rates and laryngeal lowering (McElligott \& Hayden, 1999; Charlton \& Reby, 2011). The fact that the time spent vocalizing over the rut is correlated with the number of matings gained in European fallow deer (McElligott et al., 1999), suggests that this is possible. Ultimately, differences in the call structure of the two populations are likely to result from drift rather than some form of vocal learning (Endler, 1992; Braune et al., 2008; Briefer \& McElligott, 2012).

\section{Conclusion}

Knowledge of breeding vocalizations is important for an understanding of sexual selection (Andersson, 1994; Briefer et al., 2010; Wyman et al., 2011). Our study shows that despite a long divergence period, the rut vocalizations of Persian and European fallow bucks have remained surprisingly alike. Similarly, those of two separate populations of European bucks have not changed much over a relatively short period of a few hundred years (Reby \& McComb, 2003b; Hassanin et al., 2012).

\section{Acknowledgements}

We thank Ben Rosenberg and the Israel Nature and Parks Authority for permission to carry out recordings in Israel. Joanna Stachowicz was supported by a grant from the Swiss Academy of Sciences. She was assisted by Liat Henson, Yakub Maklada and Igal Miller. We thank Prof. Guy Bar-Oz and the University of Haifa for support. We thank the Office of Public Works and staff for access to Phoenix Park and support. Financial support for Elisabetta Vannoni was provided by the Forschungskommission der Universität Zurich and Swiss Academy of Sciences. We thank David Whitby and The National Trust for access to Petworth Park. Ben Pitcher was funded by a Fyssen Foundation fellowship. Elodie Briefer was funded by a Swiss National Science fellowship. We thank Alexandre Hassanin and Yannick Wurm for phylogenetics advice.

\section{References}

Andersson, M. (1994). Sexual selection. Princeton, NJ: Princeton University Press.

Asher, G.W., Berg, D.K., Beaumont, S., Morrow, C.J., O'Neill, K.T. \& Fisher, M.W. (1996). Comparison of seasonal changes in reproductive parameters of adult male European fallow deer (Dama dama 
dama) and hybrid Mesopotamian $X$ European fallow deer ( $D d$ mesopotamica $\times D d$ dama). Anim. Reprod. Sci. 45, 201-215.

Attard, M.R.G., Pitcher, B.J., Charrier, I., Ahonen, H. \& Harcourt, R.G. (2010). Vocal discrimination in mate guarding male Australian sea lions: familiarity breeds contempt. Ethology 116, 704-712.

Boersma, P. \& Weenink, D. (2011). Praat: Doing Phonetics by Computer. http://www.praat.org/

Braune, P., Schmidt, S. \& Zimmermann, E. (2008). Acoustic divergence in the communication of cryptic species of nocturnal primates (Microcebus ssp.). BMC Biol. 6, 19.

Briefer, E. \& McElligott, A.G. (2011). Indicators of age, body size and sex in goat kid calls revealed using the source-filter theory. Appl. Anim. Behav. Sci. 133, 175-185.

Briefer, E. \& McElligott, A.G. (2012). Social effects on vocal ontogeny in an ungulate, the goat (Capra hircus). Anim. Behav. 83, 991-1000.

Briefer, E., Vannoni, E. \& McElligott, A.G. (2010). Quality prevails over identity in the sexually selected vocalization of an ageing mammal. BMC Biol. 8, 35.

Cap, H., Deleporte, P., Joachim, J. \& Reby, D. (2008). Male vocal behavior and phylogeny in deer. Cladistics 24, 917-931.

Chapman, D. \& Chapman, N. (1997). Fallow deer. Machynlleth: Coch-y-bonddu Books.

Charlton, B.D. \& Reby, D. (2011). Context-related acoustic variation in male fallow deer (Dama dama) groans. PLOS ONE 6, e21066.

Ciuti, S. \& Apollonio, M. (2011). Do antlers honestly advertise the phenotypic quality of fallow buck (Dama dama) in a lekking population? Ethology 117, 133-144.

Crawley, M.J. (2007). The R book. Chichester, UK: John Wiley \& Sons.

Endler, J.A. (1992). Signals, signal conditions, and the direction of evolution. Am. Nat. 139, S125-S153.

Fernández-García, J.L. (2012). The endandered Dama dama mesopotamica Brooke 1975: genetic variability, allelic loss and hybridization signals. Contrib. Zool. 81, 223-233.

Fitch, W.T. (2006). Production of vocalizations in mammals, In Encyclopedia of language and linguistics: 115-121. Brown, K. (Ed.). Oxford: Elsevier.

Fitch, W.T. \& Reby, D. (2001). The descended larynx is not uniquely human. Proc. Biol. Sci. 268, 16691675.

Frey, R. \& Riede, T. (2013). The anatomy of vocal divergence in North American elk and European red deer. J. Morphol. 274, 307-319.

Frey, R., Volodin, I., Volodina, E., Carranza, J. \& Torres-Porras, J. (2012). Vocal anatomy, tongue protrusion behaviour and the acoustics of rutting roars in free-ranging lberian red deer stags (Cervus elaphus hispanicus). J. Anat. 220, 271-292.

Gilbert, C., Ropiquet, A. \& Hassanin, A. (2006). Mitochondrial and nuclear phylogenies of Cervidae (Mammalia, Ruminantia): systematics, morphology, and biogeography. Mol. Phylogenet. Evol. 40, 101-117.

Hassanin, A., Delsuc, F., Ropiquet, A., Hammer, C., van Vuuren, B.J., Matthee, C., Ruiz-Garcia, M., Catzeflis, F., Areskoug, V., Nguyen, T.T. \& Couloux, A. (2012). Pattern and timing of diversification of Cetartiodactyla (Mammalia, Laurasiatheria), as revealed by a comprehensive analysis of mitochondrial genomes. C. R. Biol. 335, 32-50.

IUCN. (2012). IUCN Red List of Threatened Species. Version 2012.2. <http://www.iucnredlist.org>. Downloaded on 21 January 2013.

Janik, V.M. \& Slater, P.J.B. (1997). Vocal learning in mammals. Adv. Stud. Behav. 26, 59-99.

Jolliffe, I.T. (2005). Principal component analysis. New York: Springer-Verlag.

Kewley-Port, D., Li, X., Zheng, Y. \& Neel, A. (1996). Fundamental frequency effects on thresholds for vowel formant discrimination. J. Acoust. Soc. Am. 100, 2462-2470.

Kidjo, N., Cargnelutti, B., Charlton, B.D., Wilson, C. \& Reby, D. (2008). Vocal behaviour in the endangered corsican deer, description and phylogenetic implications. Bioacoustics 18, 159-181. 
Koren, L. \& Geffen, E. (2011). Individual identity is communicated through multiple pathways in male rock hyrax (Procavia capensis) songs. Behav. Ecol. Sociobiol. 65, 675-684.

Masseti, M., Pecchioli, E. \& Vernesi, C. (2008). Phylogeography of the last surviving populations of Rhodian and Anatolian fallow deer (Dama dama L., 1758). Biol. J. Linn. Soc. 93, 835-844.

McElligott, A.G., Birrer, M. \& Vannoni, E. (2006). Retraction of the mobile descended larynx during groaning enables fallow bucks (Dama dama) to lower their formant frequencies. J. Zool. (Lond.) 270, 340-345.

McElligott, A.G., Gammell, M.P., Harty, H.C., Paini, D.R., Murphy, D.T., Walsh, J.T. \& Hayden, T.J. (2001). Sexual size dimorphism in fallow deer: do larger, heavier males gain greater mating success? Behav. Ecol. Sociobiol. 49, 266-272.

McElligott, A.G. \& Hayden, T.J. (1999). Context-related vocalization rates of fallow bucks, Dama dama. Anim. Behav. 58, 1095-1104.

McElligott, A.G., Naulty, F., Clarke, W. \& Hayden, T.J. (2003). The somatic cost of reproduction: what determines reproductive effort in prime-aged fallow bucks? Evol. Ecol. Res. 5, 1239-1250.

McElligott, A.G., O'Neill, K.P. \& Hayden, T.J. (1999). Cumulative long-term investment in vocalization and mating success of fallow bucks, Dama dama. Anim. Behav. 57, 1159-1167.

Mundry, R. \& Sommer, C. (2007). Discriminant function analysis with nonindependent data: consequences and an alternative. Anim. Behav. 74, 965-976.

R Development Core Team. (2012). R: a language and environment for statistical computing. Vienna: $\mathrm{R}$ Foundation for statistical computing. http://www.R-project.org

Reby, D., Cargnelutti, B. \& Hewison, A.J.M. (1999). Contexts and possible functions of barking in roe deer. Anim. Behav. 57, 1121-1128.

Reby, D. \& Charlton, B.D. (2012). Attention grabbing in red deer sexual calls. Anim. Cogn. 15, 265-270.

Reby, D., Joachim, J., Lauga, J., Lek, S. \& Aulagnier, S. (1998). Individuality in the groans of fallow deer (Dama dama) bucks. J. Zool. (Lond.) 245, 79-84.

Reby, D. \& McComb, K. (2003a). Anatomical constraints generate honesty: acoustic cues to age and weight in the roars of red deer stags. Anim. Behav. 65, 519-530.

Reby, D. \& McComb, K. (2003b). Vocal communication and reproduction in deer. Adv. Stud. Behav. 33, 231-264.

Rice, W.R. (1989). Analyzing tables of statistical tests. Evolution 43, 223-225.

Saltz, D., Bar David, S., Zidon, R., Dolev, A., Perelberg, A., King, R. \& Berger-Tal, O. (2011). Reintroducing the Persian fallow deer Dama mesopotamica in Israel - a chronology. Anim. Prod. Sci. 51, 251-258.

Slabbekoorn, H. \& Smith, T.B. (2002). Birdsong, ecology, and speciation. Philos. Trans. R. Soc. Lond., B, Biol. Sci. 357, 493-503.

Sykes, N.J. (2004). The introduction of fallow deer to Britain: a zooarchaeological perspective. Environ. Archaeol. 9, 75-83.

Taylor, A.M. \& Reby, D. (2010). The contribution of source-filter theory to mammal vocal communication research. J. Zool. (Lond.) 280, 221-236.

Thirgood, S., Langbein, J. \& Putman, R.J. (1999). Intraspecific variation in ungulate mating strategies: the case of the flexible fallow deer. Adv. Stud. Behav. 28, 333- 359.

Vannoni, E. \& McElligott, A.G. (2007). Individual acoustic variation in fallow deer (Dama dama) common and harsh groans: a source-filter theory perspective. Ethology 113, 223-234.

Vannoni, E. \& McElligott, A.G. (2008). Low frequency groans indicate larger and more dominant fallow deer (Dama dama) males. PLoS ONE 3, e3113.

Vannoni, E. \& McElligott, A.G. (2009). Fallow bucks get hoarse: vocal fatigue as a possible signal to conspecifics. Anim. Behav. 78, 3-10.

Vannoni, E., Torriani, M.V.G. \& McElligott, A.G. (2005). Acoustic signaling in Cervids: a methodological approach for measuring vocal communication in fallow deer. Cogn. Brain Behav. 9, 551-565. 
Wyman, M., Charlton, B.D., Locatelli, Y. \& Reby, D. (2011). Variability of female responses to conspecific vs. heterospecific male mating calls in polygynous deer: an open door to hybridization? PLOS ONE 6, e23296. 